\title{
UNA MIRADA DESDE LA ANIMACIÓN SOCIOCULTURAL A LA CAMPAÑA DE CULTURA ALDEANA (1934-1938)
}

\author{
A VIEW FROM THE SOCIOCULTURAL ANIMATION TO VILLAGE CULTURE CAMPAIGN (1934- \\ 1938)
}

Astrid Bibiana Rodríguez Cortés ${ }^{1}$

\section{Resumen}

\begin{abstract}
En este documento se hace una mirada sobre la corriente de la animación sociocultural, la cual, para el grupo de investigación ha sido concebida como una de las tendencias que han motivado la consolidación de la recreación y el ocio como fenómenos de: intervención sociocultural, estudio y producción académica. En tal perspectiva, lo que se pretende mostrar es cómo aspectos que son trabajados en la animación sociocultural, pueden tener puntos de encuentro con lo sucedido en Colombia en lo que se denominó "Campaña de la Cultura Aldeana", la cual, se puso en marcha durante el gobierno de Alfonso López Pumarejo (1934-1938). Está campaña tenía como propósito fundamental elevar el nivel cultural de la población, para ello se diseñaron una serie de estrategias que son enclaves para encontrar algunos relaciones con lo que entendemos hoy por recreación y ocio como agentes de transformación cultural y social.

Es importante no olvidar que estos procesos históricos surgen en el marco de los proyectos de modernización que a principios del siglo XX se instauran en el país. Con miras a alcanzar estos proyectos civilizatorios, los deportes, la moda, el tiempo libre y el entretenimiento son determinantes para modificar las formas de vida de asumirse sujeto moderno.
\end{abstract}

Palabras claves: animación sociocultural, cultura aldeana, recreación, ocio, educación.

\section{Abstract}

This paper takes a look at the current animation of which, for the research group has been conceived as one of the trends that have led to the consolidation of recreation and leisure phenomena: sociocultural intervention study and production academic. In this perspective, the aim to show here is how aspects are worked on Socio may have points of contact with what happened in Colombia as Campaign Aldeana Culture, which was launched in denominate the government of Alfonso Lopez (1934-1938). Campaign's purpose was primarily to raise the cultural level of the population, to do a series of strategies that are enclaves to find some relationship with what we mean today by recreation and leisure as agents of cultural and social transformation were designed.

It is important to remember that these historical processes arise in the context of modernization projects in the early twentieth century are established in the country. In order to achieve these civilizing projects, sports, fashion, leisure and entertainment are key to change the lifestyles of modern subject assumed.

Keywords: sociocultural animation, cultura aldeana, recreation,leisure, education.

Fecha de recepción: 6 de octubre de 2014

Fecha de aprobación: 20 de marzo de 2015

Para citar este artículo:

Rodríguez, A.B. (2015). Una mirada desde la animación sociocultural a la campaña de cultura aldeana (1934-1938). Lúdica Pedagógica, (21), 175-184.

\footnotetext{
1 Doctoranda en Estudios Sociales de la Universidad Externado de Colombia. Magíster en Educación, especialista en Altos Estudios del Deporte, licenciada en Educación Física. Profesora investigadora del programa Licenciatura en Recreación y Turismo de la Universidad Pedagógica Nacional. Coordinadora del proyecto de investigación "Pedagogía y metodología de la recreación en la escuela” vigencia 2013. Facultad de Educación Física. Correos electrónicos: abrodriguez@pedagogica.edu.co, astridbibianarc@yahoo.com
} 


\section{A MODO DE INTRODUCCIÓN}

Al considerar la animación sociocultural (ASC) una tendencia de la recreación, aspecto a trabajar en este documento, pone en relieve la importancia del desarrollo educativo, social y cultural de una comunidad, no solo desde el compromiso individual sino más bien desde iniciativas que en algunos casos pueden partir de la responsabilidad estatal o el trabajo de colectivos sociales, que buscan mejorar y transformar ante todo la calidad y forma de vida de los sujetos y la sociedad.

En la primera parte del texto se hace una mirada histórica a la corriente de la animación sociocultural (ASC), para así develar sus cercanías con la educación popular y del tiempo libre en Europa y las diferencias que pueden existir con Latinoamerica. En la segunda parte se trabaja el caso de desarrollo cultural y social de la población colombiana a través de: la Campaña Cultura Aldeana (1934-1936), acontecimiento que, a partir de estrategias estatales, permitió comprender algunas apuestas por la transformación cultural y social de la población colombiana, en los primeros años del siglo XX. En la tercera y última parte se plantean algunos encuentros entre la ASC y la Campaña de Cultura Aldeana.

Con las reflexiones que se hacen en este documento no se pretende afirmar que la Cultura Aldeana es un antecedente o que, quizás, fue concebida en ese momento histórico con el espíritu de la ASC; pero sí se quiere visibilizar la postura por una transformación cultural y social que contiene este hecho histórico, el cual puede llevar a aquellos estudiosos del campo de la recreación y el ocio a escudriñar con cuidado la historia y ver la importancia de algunas medidas o políticas que se han dado en Colombia y que han alterado la vida cultural y social de sus habitantes.

\section{PUNTOS CLAVE DE TRABAJO DE LA} ANIMACIÓN SOCIOCULTURAL

La ASC es un término que ha venido acuñando diferentes acepciones y procedencias, situación que hace confuso y complejo remitirse a una sola noción u origen. Así que en este escrito se pretende abordar algunas concepciones sobre la ASC y sus diferentes sentidos, hasta llegar a asumirse como tendencia de la recreación.
Jean Augustin y Jean Gillet (2000/2003), realizan un trabajo investigativo denominado La animación sociocultural, la cual da cuenta de cinco aspectos: [1] el surgimiento de la animación profesional, [2] la educación popular y la emergencia de la animación, [3] conformación del sistema de animación, [4] actores y fundamentos y finalmente [5] retos y perspectivas de la animación, todo ello en el contexto francés.

El surgimiento de ASC estuvo ligado a la organización benéfica, a finales del siglo XIX. Varios factores de tipo social se dieron en favor de la multiplicidad de organizaciones de juventud, principalmente la lucha contra los riesgos de tuberculosis y raquitismo, así como la promoción del higienismo y las acciones médicas, poniendo a disposición de los jóvenes citadinos los primeros centros vacacionales al aire libre. Otras circunstancias eran las consideraciones de orden nacionalista que estaban centradas en preparar la revancha contra Alemania, y la baja natalidad y la mortalidad infantil que denunciaban "el desmejoramiento de la raza" (comillas del autor) (Augustin y Gillet, 2003, p. 28).

Dos periodos evidencian los autores en la organización de los movimientos de juventudes: el primero comprendido entre 1880-1939, cuando a través de las redes sociopolíticas se crearon nuevas instituciones de socialización que se interesaron, al principio en el cuidado de los niños de primaria de las ciudades, ya que los niños más grandes debían trabajar; entre las dos guerras se propusieron proyectos educativos globales a través de los movimientos juveniles que poco a poco se extendieron hasta involucrar a los niños mayores. Estas instituciones se organizaron gracias a la sociedad civil y fueron poco dependientes del Estado. En el segundo periodo se presentó un encuentro forzado entre las redes de educación popular y el Estado, en el cual el proceso de intervención de este último fue poco, pero en 1936 gracias al gobierno de Vichy de reglamentar, organizar y controlar las organizaciones de educación popular y juveniles comenzaron unas nuevas formas de adaptación y oposición que modificaron el sistema de ASC (Augustin y Gillet, 2003, p. 29)

Esta investigación muestra de manera documentada los procesos políticos y sociales que sufrió la ASC en Francia, además de las distintas tensiones que se presentaron en la relación con la Iglesia y el Estado. Sin embargo, no se puede olvidar que principalmente "la 
animación hace énfasis en las potencialidades y los procesos, los cambios y las innovaciones, más que en las carencias y en los obstáculos" (Augustin y Gillet, 2003, p.103)

Rafael Mendia (1986), en la ponencia Claves para elaborar una historia de la animación sociocultural en Euskadi, plantea inicialmente la dificultad de reconstruir una historia de la ASC en Euskadi; sin embargo, de manera general se remite a distinguir la llegada de la corriente europea con el llamado "Estado de bienestar"; la corriente norteamericana con la "civilización del ocio", y la corriente latinoamericana desde los trabajos realizados por Pablo Freire, como elemento liberador de la opresiones del pueblo.

Para Mendia (1986), son precisamente los textos de Pablo Freire en los años 1968-1970, que llegan a España, planteando nuevos conceptos en el trabajo educativo y trabajo social, los que permitirán plantear nuevos conceptos como concientización, educación liberadora, cultura popular, abriendo paso a nuevas prácticas en los programas de desarrollo comunitario. Lo que se pretendía era que la educación popular buscará sujetos que reconocieran su propio proceso histórico-cultural. Por tanto, desde su perspectiva, esta corriente concibe "la ASC como proceso de conciencia que una comunidad hace de cara a la resolución de sus propios problemas y se organiza para hacer frente a la solución de los mismos" (p. 3).

En tanto, el arribo en la década del sesenta de la corriente europea ASC tendrá sus bases en la transformación de los intercambios culturales, es decir, crea una forma de producción cultural amplia, rompiendo la idea de una cultura elitista, promoviendo una cultura abierta, pluralista y democrática, recurriendo a los mass media como el radio y la televisión que cumplieron un papel importante en este proceso.

Anteriormente la cultura se reducía al conjunto de la literatura, música, artes plásticas o patrimonio cultural y a los géneros llamados elevados o nobles, pero de ahora en adelante va adoptando los géneros que hace años se consideraban minoritarios o populares; se sitúa en el presente como en el pasado y comprende —además del aspecto estético: literatura, música, artes plásticas- un aspecto científico (ciencias y tecnología), un aspecto físico (deportes, vida al aire libre) y un aspecto social: el hombre en su trabajo, en su medio de vida, en la economía, en la política (Mendia, 1986, p. 4).
Este autor contempla que los aportes de Dumazedier (1964), en su trabajo Hacia una civilización del ocio, donde se plantean "las tres D" (descanso, diversión y desarrollo), así como las teorías sobre el tiempo libre logran penetrar los conceptos y prácticas de la AS en Europa. Para Mendia (1986),, un movimiento intermedio que llega a Euskadi "es la educación en el tiempo libre, el tiempo libre como ámbito educativo" (p. 4), ya que este movimiento trata de casar un planteamiento liberador de la educación con algunas consideraciones sobre el ocio y el tiempo libre que tienen como fin el desarrollo personal y social.

Se destaca de este texto las diferencias que presenta con relación a los distintos modelos de ASC que llegan a Euskadia, de esta manera se comprende, tal como lo plantea el autor, que los límites entre la educación popular, la educación del ocio, la educación en el tiempo libre, son confusos y están íntimamente ligados.

En tanto, Pierre Besnard (1988), en su texto "Problemáticas de la animación sociocultural", plantea cómo el campo de ASC en Francia tiene aún mucho por hacer. Desde su perspectiva, la ASC es un fenómeno que surge en el seno de la educación popular en los años 1960-1970. Sin embargo, Besnard comenta, cómo en los años 1970-1975 los trabajos consultados muestran una ruptura con la educación popular. Simonot (citado por Besnard, 1988) señala que dicho cambio o ruptura tiene que ver con los cambios en los objetivos del movimiento de educación popular, estableciendo diferencias notorias con la ASC, en particular, con relación al tema de la escuela, "de la que tiende a separarse suprimiendo las referencias directas a la transmisión de saber, de valores, situándose en el punto de vista de los individuos y de los grupos, y ya no del exterior" (p. 19). Sin embargo otro grupo de animadores socioculturales consideran que al igual que la educación popular la ASC se originó por movimientos sociales de reivindicación cultural dirigidos por grupos y asociaciones voluntarias, animados por militantes (comillas del autor) culturales que subsanarían algunas desigualdades sociales y que en algunos casos se reprodujeran en la escuela (Besnard, 1988).

Así mismo, la ASC estuvo vinculada al desarrollo de las sociedades industriales que modificaron los modelos culturales, gracias a estos profundos cambios sociales que se experimentaron, la ASC 
[...] desempeña una función de antídoto eficaz a esa patología de la vida social, resultado de las rupturas de comunicación, del aislamiento individual, de la pérdida de las pautas de referencia tradicionales y de todas las garantías metasociales que cubrirían la seguridad existencial del individuo (Besnard, 1988, p. 21)

Así, la animación se presentó como intermediario entre la creación, los nacientes modelos culturales y la participación de las masas en esa producción e incluso en esta creación (p. 22). Por tanto, para Besnard, la ASC cumple un papel de facilitador en la adaptación a los cambios que afectan a la sociedad y la cultura, permitiendo reducir las desigualdades de participación en el propio poder de la sociedad. Esta perspectiva del surgimiento de la ASC en Francia permite ver las diferentes configuraciones e ideologías al interior de este movimiento, sin embargo se resalta el trabajo cultural y mediador que este autor propone, es decir, se presenta a la ASC como intermediario entre las políticas culturales del Estado y las acciones y expresiones de individuos y grupos sociales, lo cual facilita la participación activa en el desarrollo social.

Úcar (s.f.) señala la dificultad de establecer el momento exacto de una profesión o concepto, sin embargo señala que el término animación fue utilizado por primera vez en el Ministerio francés de Educación Nacional en 1945. Con esta nueva denominación se caracterizaba a una serie de agentes sociales herederos del movimiento de educación popular "que desarrollaban acciones socioeducativas y culturales con personas, grupos y comunidades en sus propios ámbitos territoriales de vida cotidiana" (p. 1). Al centrar su llegada a España, la ubica como una práctica que se ha construido desde el desarrollo comunitario, estableciéndola como defensora de las libertades en comunidades y territorios, y segundo como una herramienta de intervención socioeducativa que recobraría la dinamización y el tejido social en los barrios (p. 1).

Para determinar los orígenes de la ASC es necesario centrarse en las crisis de las civilizaciones occidentales, entendidas a partir de las dos grandes guerras mundiales y "sobre todo a partir del periodo transcurrido desde el final de la segunda hasta el momento actual" (Úcar, 1992, p. 9), para Úcar la ASC surge en un contexto pluri- y multiforme como respuesta a los diferentes desequilibrios generados por efecto de la crisis $^{2}$, se fundamenta en cuatro tipos de factores contextuales que cimientan no solo su evolución sino su metodología de intervención socioeducativa:

1. El socioeconómico, donde se cita el desarrollo tecnológico, el proceso de urbanización y el proceso de burocratización, como parte fundamental de la modernización social, conllevando al aumento de la movilidad geográfica, la homogenización urbana, el desarraigo de los centros urbanos y la pérdida de la identidad cultural, generando graves problemas en el entramado social.

2. El político, que no puede ser analizado sin tener en cuenta el anterior contexto. A partir de los años 1950-1960 desde la concepción de los "Estados de bienestar", el cual se caracterizó por: a) un fuerte intervencionismo estatal, b) la democracia de masas y c) el Estado social o Estado benefactor, el cual tuvo consecuencias como: la expansión estatal, una privatización política y social, un cambio en la estructura social y en las vías tradicionales de conflicto, que generaron una institucionalización de la lucha de clases y mejoraron de manera generalizada las condiciones de vida, que contribuyen a neutralizar de alguna manera la dinamización social.

3. El cultural, lo más fuerte para este autor es el concepto y contenido que había tenido la cultura en los últimos cuatro decenios, lo que constituye la causa principal del nacimiento de ASC, ya que la cultura había estado reservada a algunos pocos. Por ello, se comienza todo un movimiento donde se democratiza la cultura, que se concreta en la llamada cultura de masas, y su máxima expresión será a través de los medios de comunicación de masas, en la difusión cultural. Sin embargo, los que generaban la cultura eran unos pocos y los que la consumían eran la gran mayoría. En tal sentido, se puede observar la cultura como objeto de consumo, llevando ello a la creación de las grandes industrias culturales, que 
homogenizan y uniforman a los consumidores. Así, se genera una incapacidad de autoorganización y gestión del tiempo libre.

4. El educativo, ante lo planteado por los tres contextos anteriores, se establece la distancia del sistema educativo y la realidad social de complejidad creciente. Sin embargo, se reconoce el intercambio de métodos y experiencias que han llevado a que la ASC se haya nutrido de la relación con otros modelos educativos como el caso de la educación popular, la educación de adultos, educación permanente, educación en el tiempo libre, educación extraescolar y pedagogía del ocio (Úcar, 1992, pp. 13-14).

Este análisis contextual que hace el Úcar permite entrever problemáticas sociales que han correspondido sobre todo después de la segunda mitad del siglo XX, donde la cultura se vuelve un objeto de consumo que se masifica y construye relaciones sociales individualistas y poco comprometidas con la acción social, producto de estos factores contextuales, "en los años 2000 se habla poco de animación sociocultural [...]. En los últimos veinte años se ha pasado de un discurso vivo, dinámico, esperanzador e incluso macrocomprensivo a un discurso inexistente" (Úcar, s.f., p. 10).

Por su parte, Joseú Llull Peñalba, en su libro Teoría y práctica de la educación en el tiempo libre (1999), plantea que la educación del tiempo libre ha ampliado su radio de acción hacia planteamientos propios de la ASC. Ambos movimientos han tenido proyecciones paralelas desde los años 1960; para él se encuentran profundamente conectadas. La diferencia entre la una y la otra es que la primera tiene características más lúdicas, festivas y sus proyectos se han destinado más a niños y jóvenes, mientras que la ASC se ha configurado en una perspectiva más teórico conceptual, más planificada en sus acciones y promovida incluso políticamente, destinándose principalmente a los adultos y a la tercera edad.

Ventosa (citado por Llull, 1999) comenta cómo los orígenes de la ASC están ligados a la escuela, desde programas educativos integrales e interdisciplinarios con actividades extraescolares, como lo fueron las colonias escolares. Así la ASC fue una estrategia básica de la pedagogía social, la cual pretendía el desarrollo socioeducativo de los individuos y comunidades:

La ASC ha ido introduciéndose en la enseñanza reglada como estrategia de motivación hacia los procesos de aprendizaje, como metodología adecuada para ampliar y diversificar los ámbitos de intervención educativa y como conjunto de actividades no formales o extraescolares que han ido completando los programas formativos de los centros docentes. Ahora vamos a referirnos a otra dimensión muy interesante de la ASC en la escuela: la dinamización de la comunidad educativa (Llul, 1999, p. 194).

Interesante aquí el papel que se adjudica a la escuela como parte del surgimiento de la ASC, así como a las actividades extraescolares que permitirían reconocer esa relación de la escuela con las prácticas de dicho movimiento social. Este es un aspecto que no ha sido común en los autores previamente aquí citados, quienes, como se ha mostrado, han establecido por un lado otros factores e instituciones al surgimiento de la ASC, por otro lado, tal como lo mostró Besnard (1988) puede existir diferentes posiciones sobre la relación que se pudo establecer entre la ASC y la escuela.

El escritor argentino Ezequiel Ander-Egg (1987), en su libro ¿Qué es la animación sociocultural?, comenta cómo la emergencia de esta, surge en los años 60 en algunos países europeos y su mayor desarrollo lo alcanza en las dos décadas siguientes. Según ese autor, la ASC nace emparentada con la educación popular, en Francia y Bélgica, desde finales del siglo XIX, en procura de la democratización de la cultura escolar. Sin embargo, en la experiencia alemana, lo que se puede llamar hoy ASC, estaría vinculada con la pedagogía social.

Para Besnard (1987) también es claro que la ASC desde el primer momento nace como una forma de educación, pero no de cualquier educación, sino que tiene que cumplir las siguientes características:

- Es parasistemática: las actividades y la función de formación se realiza fuera de la institución educativa.

- Tiene un carácter promocional y reinvindicativo de los sectores menos favorecidos.

- No solo le preocupa la transmisión de conocimientos sino también la comprensión de los fenómenos socioculturales. 
- Se apoya en la iniciativa y supone la preparación de la gente para que se asuman y participen en su propio desarrollo personal.

- Con la ASC se busca que los individuos se organicen y participen como un medio de promoción y emancipación.

- Uno de los aspectos que más se trabaja es en dinamizar la vida cultural a través de la participación de la misma gente.

Para Ander-Egg (1987) es claro que:

Desde su nacimiento de la ASC es una forma de intervención sociopedagógica, de promoción cultural o de acción social [...] que procura que la gente se sitúe como agente activo de su propia formación. En esto se diferencia de la educación popular (versión europea, lo advertimos otra vez) que tenía un estilo pedagógico más transmisivo y paternalista y consecuentemente menos crítico (p. 66).

Tal como lo presenta Ander-Egg el trabajo de la ASC se centra en un desarrollo cultural y social donde la participación de la gente es fundamental para lograr la comprensión de fenómenos socioculturales contextualizados, que permitan una intervención sociopedagógica en procura que las personas se reconozcan como agentes activos de su propia formación.

En tanto, Pablo Waichman (2009) se ha dado a la tarea de sistematizar algunos de los alcances sociales que ha tenido la recreación en tendencias o corrientes que con distintos enfoques teóricos fundamentan el desarrollo práctico de la misma, ellos son: el recreacionismo o corriente norteamericana, la animación sociocultural o corriente europea y la recreación educativa. Para Waichman, la ASC tiende a la búsqueda de un cambio de actitudes en las personas y grupos llevándolas a participar, consciente y comprometidamente, en la generación de acciones y procesos de dinamización popular, destinados al desarrollo comunitario y mejoramiento de la calidad de vida de la sociedad con valores distintos a la sociedad individualista.

Desde un punto de vista crítico, Waichman plantea que la corriente del recreacionismo y la ASC:

Comparten una desafortunada noción de ocio y tiempo libre (en francés, loisir). En ambos modelos prevalece la contradicción obligación/ocio y tiempo ocupado/tiempo libre. Con una concepción centrada en las ideas de Dumazedier se plantea que el ocio es un conjunto de ocupaciones a las que el individuo puede dedicarse voluntariamente, sea para descansar o para divertirse, o para desarrollar su información o su formación desinteresada, su voluntad de participación social o su libre capacidad creadora (p. 104).

Se rescata fundamentalmente del texto de Waichman, el planteamiento que hace al retomar la ASC como una de las corrientes de la recreación, centrado principalmente en Europa su quehacer y además con una perspectiva crítica haciendo una comparación con el recreacionismo norteamericano, que desde su punto de vista se tiene una visión restringida de la recreación planteándola como facilitadores de la renovación de fuerzas físicas y espirituales.

A manera de análisis, se quiere resaltar algunos puntos claves de lo expuesto:

- La ASC tiene como fin trabajar por unas mejores condiciones de vida con relación al acceso cultural y social de una comunidad.

- Si bien es cierto la ASC está ligada a la educación, no se tiene total certeza frente a si su surgimiento tiene que ver con realización de actividades extraescolares como una manera de ocupar el tiempo libre de los estudiantes, o por otro lado, como una estrategias de educación popular de las organizaciones fuera de la institución escolar.

- En general los autores estudiados en este documento coinciden en precisar que las formas de socialización sobre las cuales se basa la ASC tienen que ver con actividades en torno a deportes, cine, teatro, bibliotecas y actividades al aire libre.

- En la historia de la ASC, se reconoce en general una relación tripartita entre Iglesia, Estado y movimientos sociales. El protagonismo de cada uno de estos estamentos se ha dado según el contexto histórico.

- Las acciones en las que trabaja las ASC promueven la construcción de espacios no solo físicos sino relacionales que permiten la sociabilidad e interacción entre los sujetos de una comunidad fortaleciendo sus representaciones políticas y las prácticas que trabajan en pro de la cultura y la sociedad. 
- En general los autores coinciden en la dificultad para poder definir lo que es la ASC, es más fácil reconocer sus prácticas, que una conceptualización propia que la sustente.

- Se reconoce que históricamente la ASC ha trabajado con comunidades como los jóvenes, los niños sin escolarización y, sobre todo, los adultos mayores.

- El movimiento de ASC es de carácter comunal y pretende además de una transformación cultural y social, un mundo donde en esencia la colaboración y el servicio al otro contribuyan a un desarrollo humano muchos más equitativo y recíproco; por ello, es fundamental reconocer como eje de su trabajo, la asociación y la participación local, permitiendo la emergencia de nuevas formas de progreso social más democrático, responsable y activo del ejercicio de lo que implica la ciudadanía.

Los puntos aquí enunciados son enclaves que facilitan una mirada reflexiva sobre un suceso histórico que se dio en Colombia en los años 1930. Por su puesto y como se indicó al inicio, se asume la ASC como una tendencia de la recreación, en este caso, se convierte en una forma de mirar, en unos lentes de análisis desde los cuales se quiere leer.

\section{EL CASO DE LA CAMPAÑA DE CULTURA ALDEANA}

La Campaña de Cultura Aldeana fue un proyecto político-cultural que se llevó a cabo en Colombia por el presidente Alfonso López Pumarejo (1934-1938). Tal iniciativa, se enmarcó en el proceso de modernización de la sociedad colombiana, el cual tenía como fin modificar la forma de vivir de los sujetos, a partir del desarrollo industrial, la producción de bienes y servicios y su consumo, y la aceleración de la vida en sí misma; así se crearían unos nuevos sujetos de la modernidad, que pensaran, actuaran y sintieran en consonancia con los modelos culturales de las nuevas sociedades urbanas e industriales en construcción.

Después de un largo periodo de influencia conservadora (1885-1930), llega al poder el liberalismo (1930), que buscaba la modernización del país, en este caso Alfonso López Pumarejo; su gobierno se caracterizó por ser reformista, realizando cambios en los ámbitos agrarios, constitucionales y educativos, principalmente "la educación empezó a ser entendida y realizada en función de objetivos políticos de Estado a partir de los cuales se buscó mantener su coherencia y armonía como totalidad" (Sáenz, Saldarriaga y Ospina, 1997, p. 267). Esta mirada de totalidad lleva a focalizar grandes problemas en el campo educativo, uno de ellos, el analfabetismo de la población rural, lo que constituía un obstáculo para llegar a la modernización del país, por tanto, uno de los primeros propósitos era fortalecer la educación pública colombiana, rediseñando las relaciones entre Iglesia, Estado central y congregaciones religiosas (p. 268).

El gobierno de López se preocupó por el nacionalismo, el valor de lo propio, lo autóctono, en una palabra, la cultura propia y el papel que ella tenía en la escuela, implicando ello que los maestros comprendieran que la escuela no estaba dada solo en la aceptación de propuestas de contenidos curriculares sino que podía incidir en el medio cultural y social de la nación. El ministro de Educación de la época, Luis López de Mesa (1936-1938), un intelectual preocupado por elevar los niveles educativos de la población colombiana, entendía la cultura como "el conjunto de hipótesis con que un pueblo en determinado estado mental interpreta el mundo" (citado por Sáenz, Saldarriaga y Ospina, 1997, p. 286). Está concepción lleva a diseñar la estrategia de Campaña de Cultura Aldeana, la cual tenía como objetivo difundir conocimientos que transformaran la mentalidad colombiana, así como, conocer la realidad de la nación; para lograrlo, el gobierno priorizó las aldeas y las escuelas:

Para ello se tomó como referencia a las aldeas: pueblos que tenían entre quinientos y cinco mil habitantes y, a las escuelas, como escenarios privilegiados, donde el Gobierno nacional, a través del Ministerio de Educación Nacional, haría llegar radio, cinematógrafo, planos arquitectónicos para la construcción de escuelas y centros comunales, profesores ambulantes, inspectores de educación y restaurantes escolares, así como las Bibliotecas Aldeanas (Herrera y Díaz, 2001, p. 105).

Esta campaña intentó cambiar el pensamiento de los colombianos que se encontraban en los campos, recurriendo a recursos tecnológicos y a nueva infraestructura. Se promovió una manera de pensar más amplia 
así como unas nuevas formas de integración social. Este esfuerzo se destacó por atender los sectores populares de la nación colombiana y permitió la entrada de nuevos discursos y formas de concebir la sociedad en sí misma:

El propósito fundamental de la Campaña de Cultura Aldeana fue la transformación de la vida rural de Colombia y pretendía instaurar una nueva manera de sentir, pensar y actuar en el pueblo, para acercarlo a los principios de la higiene y de la estética que imponía el periodo (Díaz, 2005, p. 100).

La campaña se empezó a realizar en las aldeas que tenían las características enunciadas, la estrategia era llevar libros, bibliotecas, cinematógrafo, radio y personajes como médicos y maestros ambulantes para preparar a los campesinos en un hacer cada vez más tecnológico; además era necesario que los alcaldes, diligenciaran unas encuestas que describirían aspectos importantes de sus municipios, con la intención de hacer un diagnóstico sobre la población y en definitiva del país (Díaz, 2005, p. 103).

Se destaca en la aplicación de esta campaña la construcción de parques, salones culturales, calles, escenarios deportivos, los cuales permitieron percibir unas relaciones distintas entre lo político, lo cultural y lo social. La edificación de estos nuevos escenarios de socialización contribuyeron a la cimentación de nuevas maneras de configurar los sujetos de la modernidad, los cuales requerían de mayores conocimientos centrados en la lectura y la escritura, una racionalidad en la organización del tiempo, unas pautas de comportamiento urbano y social diferente y una aplicación de conocimientos técnicos adecuados.

Paralelo a todo lo anterior, López de Mesa en 1937 propuso la creación de las colonias escolares de vacaciones, que se centraban en la defensa de la infancia a partir de un discurso biológico y eugenésico que pretendía mejorar la salud de los infantes, así como depurar la raza; esta táctica conllevaba acciones como ejercicios físicos, juegos, excursiones, lecturas al aire libre, aseo y cuidado personal (Sáenz, Saldarriaga y Ospina, 1997, p. 317).

Estas estrategias que se concentraron en las aldeas seleccionadas crearon un ambiente que focalizó el trabajo cultural y social, su énfasis era cambiar la conciencia educativa. Para lograrlo, el cine y la radio se convirtieron en herramientas claves en la educación de la población adulta, la elaboración de cartillas instructivas en higiene y aspectos morales permitieron el avance moral y cultural del país, la construcción de escenarios de socialización configuró otras formas de entretenimiento y diversión alternas a la chichería. El reordenamiento urbanístico de las aldeas permitió no solo un cambio en las estéticas sino la imposición de nuevas formas de vida rural y comportamiento social.

Uno de los legados importantes que dejó esta campaña fue la organización en torno a la escuela; para 1940 se establecieron los patronatos escolares nacionales y municipales, los cuales, "por medio de la colaboración de los particulares en los programas del ministerio, estaban dirigidos a mejorar el nivel de vida de las clases populares y a proteger la clase obrera" (Sáenz, Saldarriaga y Ospina, 1997, p. 307).

Como se puede observar, la consagración de la Campaña Cultura Aldeana tenía una propuesta por la modernización del país, para lo cual su herramienta fundamental fue pensar en el acceso cultural a partir de múltiples estrategias que apuntarían a configurar un tipo de sujeto moderno, con mayores conocimientos y con niveles culturales más amplios.

\section{¿CUÁLES SON ENTONCES LAS POSIBLES RELACIONES ENTRE LA ANIMACIÓN SOCIOCULTURAL (ASC) Y LA CAMPAÑA DE CULTURA ALDEANA?}

Es necesario recordar que el contexto educativo de los años 1930 en Colombia, según autores como Zandra Pedraza (1999); Ximena Herrera (2012); Javier Sáenz, Óscar Saldarriaga y Armando Ospina (1997), entre otros, manifestaba una preocupación por el debate eugenésico, donde para tener una cultura era necesario tener un cuerpo y mente sanos. Así que los principios de eugenesia e higiene estaban interpelando las políticas, las prácticas educativas y sociales colombianas.

Sin olvidarlo y por supuesto sin dejar de lado el contexto educativo y social, este documento se centra en visibilizar las políticas culturales y sociales de López de Mesa. En esta perspectiva, el énfasis de la Campaña de Cultura Aldeana fue lograr el progreso social, por medio de visibilizar la cultura propia, tal sentido, difundió modos de vida que intentaron interpelar las 
subjetividades tanto de las élites como de los campesinos colombianos.

Desde el marco de la ASC, aspecto analizado en la primera parte de este documento, se puede afirmar que la Campaña de Cultura Aldeana facilitó una manera de promover el desarrollo cultural y social del país. Como se mostró con Augustin y Gillet (2000/2003), la historia de la ASC en Francia estuvo marcada por las diferentes tensiones, pero así mismo formas que encontraron las asociaciones para trabajar fuera del Estado, con las políticas del Estado y en oposición a este, se destaca precisamente que no en todas las ocasiones, las asociaciones y acciones de la ASC han sido producto de la organización civil, sino que también estos movimientos se han dado a partir de políticas culturales institucionales, o por otro lado, como oposición a estas, por ello, no se asume aquí una sola visión tanto del surgimiento, de su trabajo y acciones, sino que la ASC desde los referentes estudiados ha sido ecléctica pero efectiva, en tanto ha puesto la cultura y el desarrollo social como su objetivo fundamental, por tanto, lo que se pretende mostrar es cómo en un momento histórico particular en Colombia, la Campaña Cultura Aldeana liderada desde la institucionalidad trabaja por poner la cultura en un primer plano.

En tal sentido, se considera que a esta campaña fue sin duda uno de los mayores intentos que ha tenido el país por pensar desde el Estado, políticas y acciones que propendieron por mejorar los niveles culturales y sociales colombianos, desde la educación y la escuela. Tal como lo sugiere Díaz (2005), en su revisión documental, los autores señalan cómo el programa de Cultura Aldeana fue el "primer intento de revolucionar la escuela rural poniéndola al servicio de un ideario liberal y de unas aspiraciones innegablemente populares. (p. 34).

Se observa con cuidado como las estrategias usadas son las mismas que proponen los autores estudiados en la ASC, entre otras: los medios masivos de comunicación, las actividades deportivas, la construcción de nuevos escenarios de socialización, las cuales tienen como fin crear ambientes de encuentro que permitieran abrir espacios de comunicación y trabajo social ejerciendo mejores formas de vivir en comunidad.

Como ya se mencionó, existen diferentes concepciones sobre la relación que tiene la escuela como institución en algunos momentos históricos de la ASC, en tanto, lo que propone la Campaña de Cultura Aldeana era el reconocimiento de la escuela como eje promotor de nuevas formas de concebir la cultura, además de considerarla centro de trabajo para las asociaciones que posteriormente surgirían como son los patronatos educativos y las asociaciones de padres. Sin embargo, esta campaña también trabajó fuertemente en la educación de adultos y de la población en general, a partir de los medios de comunicación, a los cuales se les reconoció como nuevos agentes educativos.

Uno de los propósitos de la ASC es el desarrollo de concepciones sobre tiempo libre, el cual se puede entender como un tiempo social en el que se realizan actividades que propendan por el fortalecimiento de los sujetos y comunidades, y que conllevan a la adquisición de formas culturales amplias y facilitan el ejercicio ciudadano propositivo y pertinente. En tal sentido, es interesante lo que plantea Díaz (2005) como una de las propuestas de la Campaña Cultura Aldeana:

La amplia acción educativa y la promoción de la cultura social que la campaña proponía pasaba entonces por mostrarle a las élites locales y a los aldeanos la manera de mejorar su poblado, pero igual importancia merecía la construcción de nuevos espacios, de nuevos escenarios para el encuentro y el contacto entre los pobladores, aspecto que contribuiría a su socialización y configurarlos subjetivamente (p. 154).

Se puede decir que con la Campaña Cultura Aldeana leída desde el marco de la ASC, fueron orientadas distintas estrategias educativas que buscaban diagnosticar las necesidades colombianas, así como comprender las maneras en que la cultura podría llegar a ser un asunto importante de la educación y la nación. Para ello se pensó en difundir conocimientos sobre la higiene, el cuidado corporal, la salud, la moral y la forma de acceder a pensamientos de modernización, desde la escuela y los medios de comunicación masivos que intentaban consolidar una conciencia de nación diferente que apuntaba a una nueva manera de ejercer la ciudadanía. Desde esta perspectiva, se encuentran puntos de convergencia entre el espíritu de la ASC y la Campaña Cultura Aldeana, aspectos que pueden seguir siendo profundizados a la luz de las acciones realizadas y los impactos que ellos generaron en la población nacional. 
Se puede considerar que el asunto que aquí se trata, tiene en esencia mostrar la importancia de encontrar nuevos caminos para acceder, transmitir y difundir la cultura, respetando los contextos históricos y sociales, por tanto, esta búsqueda de la ASC entendida aquí como una tendencia de la Recreación es una forma más de intervenir social, política, educativa y culturalmente en la nación colombiana.

\section{A MODO DE CONCLUSIÓN}

En general, si bien es cierto que la Campaña Cultura Aldeana no se puede considerar un antecedente directo de la ASC en Colombia, sí puede ser un referente de análisis histórico que permita comprender los procesos que se han promovido desde el Estado como política cultural y educativa con estrategias y acciones que reflexionaron sobre la identidad, lo autóctono, la utilización racional del tiempo. Desde la recreación es un insumo importante para analizar formas sociales y culturales en que se ha asumido.

\section{REFERENCIAS BIBLIOGRÁFICAS}

Augustin, J.P. y Gillet, J.C. (2003). La animación sociocultural. Estrategias de acción al servicio de las comunidades. Bogotá: Universidad Externado de Colombia.

Ander-Egg, E. (1987). ¿Qué es la animación sociocultural? Tenerife: Editorial Espartaco Córdoba.

Besnard P. (1988). Problemáticas de la animación sociocultural. En: Debesse y Mialaret (1988). La animación sociocultural. Barcelona: Oikos-tau, S.A.

Díaz C. (2005). El pueblo: de sujeto dado a sujeto político por construir. Bogotá: Universidad Pedagógica Nacional.

Herrera C. y Buitrago N. (2012). Escritos sobre el cuerpo en la escuela: Sujetos, prácticas corporales y saberes escolares en Colombia. Siglos XIX y XX. Bogotá: Kimpres Ltda.

Herrera M. y Díaz C. (2001). Bibliotecas y lectores en el siglo XX colombiano: la Biblioteca Aldeana de Colombia. Revista Educación y Pedagogía 13(29-30), 103-111.

Llul, J. (1999). Teoría y práctica de la educación en el tiempo libre. Madrid: Editorial CCS.
Como se comentó el contexto educativo y social de la primera mitad del siglo XX estaba enfocado al higienismo, lo que es asumido como uno de los propósitos de la Campaña de Cultura Aldeana, sin embargo, además de trabajar e insistir en este aspecto, dicha campaña promueve un trabajo cultural y social que se empieza a preguntar por el uso racional del tiempo de los sujetos, es decir la manera en que socializan y divierten, y cómo puede ser esto asumido por los sujetos de la modernización.

En ese sentido, es importante considerar el estudio de otros procesos de organización social que en vías diferente al Estado han promovido también la transformación cultural y comunal de la sociedad colombiana.

Por ello, la invitación que se hace es a continuar con análisis históricos, que permitan comprender el sentido del presente con la luz del pasado. Este trabajo se suma a la brecha que se ha abierto desde diferentes concepciones y disciplinas para aportar a la consolidación del campo de la recreación y el ocio.

Mendia R. (1986). Claves para elaborar una historia de la animación sociocultural en Euskadi. Ponencia presentada en el Encuentro sobre Animación Sociocultural organizado por la Dirección de Juventud y Acción Comunitaria del Gobierno Vasco. 13 al 15 de noviembre. Recuperado de: http://www.rafaelmendia. com/mendia/Conferenciasfiles/claves.pdf

Pedraza Z. (1999). En cuerpo y alma: visiones del progreso y la felicidad. Bogotá: Universidad de los Andes.

Sáenz, J.; Saldarriaga, O. y Ospina, A. (1997). Mirar la infancia: pedagogía, moral y modernidad en Colombia. 1903-1946. Vol. 2. Medellín: Universidad de Antioquia.

Úcar X. (1992). La animación sociocultural. Barcelona: Ceac.

Úcar, X. (s.f.). Medio siglo de animación sociocultural en España: Balancey perspectivas. Revista Iberoamericana de Educación. Recuperado de: http://www.rieoei.org/ deloslectores/301Ucar.pdf

Waichman, P (2009). ¿Cuál recreación para América Latina? Espacio Abierto Cuaderno Venezolano de Sociología 18(1), 101-108. 